Scholars International Journal of Chemistry and Material Sciences

Abbreviated Key Title: Sch Int J Chem Mater Sci

ISSN 2616-8669 (Print) |ISSN 2617-6556 (Online)

Scholars Middle East Publishers, Dubai, United Arab Emirates

Journal homepage: http://saudijournals.com/sijcms/

\title{
Improved Performance in Bitumen Properties through Modification with Sheared Polyethyline Waste
}

\author{
G. Aladekoyi ${ }^{1 *}$, E. G. Olumayede ${ }^{2}$ \\ ${ }^{1}$ Department of Science Laboratory Technology, Rufus Giwa Polytechnic, Owo, Ondo State, Nigeria \\ ${ }^{2}$ Department of Industrial Chemistry, Federal University, Oye-Ekiti, Nigeria
}

DOI: $10.36348 /$ sijcms.2020.v03i08.001

| Received: 31.08.2020 | Accepted: 08.09.2020 | Published: 29.10.2020

*Corresponding author: Aladekoyi Gbenga

Abstract

Polymer modification of bitumen to decrease bitumen pavement susceptibility to high and low temperatures, allowing reduction in common failure mechanisms as rutting and cracking has been in existence since decade. The objectives was to study the mechanical and rheological properties of properties of extracted base bitumen from Agbabu and Loda and bitumen-polymer (polyethylene) blend from the two sources and helped to understand possible conversion of the nondegradable waste into useful product. 200grams of sheared waste polyethylene sachet were mixed in ratio 10:90, 20:80, 30:70, 40:60 and 50:50 to extracted bitumen sample from both Agbabu and loda using mechanical mixer Heidolph model RZR 2020. These were heated in a thermosetting oven at $300^{\circ} \mathrm{C}$ for two hours for good modification. The results obtained indicated that Agbabu bitumen had good yield (79.90 \pm 0.01$)$ when compared with Loda (46.50 \pm 0.01$)$ after extraction. Other physico-mechanical properties of sheared Polyethylene Modified Bitumen (SPMB) indicated that bitumen base from Agbabu is efficient and economical for road pavement. The results obtained from SPMB from Agbabu and Loda were; Penetration at $25^{\circ} \mathrm{C}$ increased from ratio 10:90 to 40:60 in both samples (47.50 $\pm 0.20-57.35$ $\pm 0.10)$ and $(46.20 \pm 0.20-52.15 \pm 0.20)$ before retreating. Marshall Stability $(\mathrm{kg})$ at $60^{\circ} \mathrm{C}$ also increased with increase in sheared polyethylene modified bitumen from $10 \%$ to $40 \%$ increase in both modifications and diminished in $50 \%$ increase. Generally the values obtained for the physico-mechanical properties increased with increase in modifiers from $10 \%$ to $40 \%$ modification in the two samples, but good performance was noted in Agbabu modification than Loda for sheared polyethylene bitumen. The rheological properties from different proportions of modification at temperature ranges from $45^{\circ} \mathrm{C}$ to $65^{\circ} \mathrm{C}$ indicated that SPMB at $40 \%$ modification is encouraged for better performance because these blends will exhibit greater stiffness at higher temperature and high flexibility at low temperatures.

Keywords: Marshall Stability, Phase angle, physico-mechanical, Rheological properties, Rutting Parameters.

Copyright (C) 2020 The Author(s): This is an open-access article distributed under the terms of the Creative Commons Attribution 4.0 International License (CC BY-NC 4.0) which permits unrestricted use, distribution, and reproduction in any medium for non-commercial use provided the original author and source are credited.

\section{INTRODUCTION}

Bitumen is widely used in most countries for road pavement. However, the performance level of service life of bitumen has relationship with the properties. The complexity of bitumen is primarily due to various sources and refining processes, but the chemical compositions are correlated with its rheological properties. The rheological weakness of conventional bitumen has generated an increasing interest, hence, the advocacy for polymer-modified binders to enhance conventional bitumen properties [1].

In recent time, modification of bitumen with polymer has become a common practice in road construction as reported by Chen et al., [1]. Studies [2] have reported that bitumen modification offer products of improves performances. These include improved fatigue resistance, improved performance in extreme climate conditions and under heavy traffic conditions, and reduce life cycle cost softer mixture of low service temperature with minimum cracking. Collins et al., [3] reported that selection of appropriate asphalt is essential to obtain a blend with optimal properties. According to Anderson et al., [4], polymer modified bitumen increased the elasticity of mix and the viscosity at high temperature. In a study on the addition of styrenebutadiene-styrene (SBS) to bitumen, Chen et al., [1] and Masson et al., [2] observed reduction in cracking and rutting of the product. Similarly, in studying the addition of polyethylene wax (PW) to bitumen, GarciaMorales et al., [5] and Polacco et al., [6] observed reduction in rutting of the asphalt. Meanwhile, Crumb Rubbers have been proven to reduce cracking and 
rutting but at reduced levels to what can be reached with SBS or PW [7, 8]. Although, bitumen modification is commonly performed by addition of thermoplastic or elastomers polymers [9], using multiple materials. Despite the improvements in properties, it is not common to find studies which have reported the utilisation of other plastomeric polymer materials, such as polyethylene and polypropylene as potential filler in bitumen for use in road paving [10]. This can be attributed to their viscoelastic properties and good adhesion to the mineral aggregates. According to Munera and Ossa [9], in a study on the mechanical and the rheological properties of bitumen filled separately with polyethylene wax and styrene-butadiene-styrene copolymer. The results showed that high level of modification was achieved with polymer-bitumen blends.

The elastomeric polymers added to bitumen build a physical network assisted by bitumen's phases but do not create a chemical reaction, leaving bitumen as a continuous phase. On the other hand, thermoplastic polymers have been also added to bitumen pursuing improvements on rutting resistance at high temperatures, making use of the hardening effect of these polymers at high temperatures.

Waste polyethylene sachets are products of plastic which are used widely for various purposes, among such function is in the packaging of pure water. This when consumed and disposed can pose a great environmental problem if not disposed properly or recycled [11].

\section{Basic Composition of Bitumen}

In bitumen, Hydrocarbon and its derivatives form a complex colloidal system to form bitumen structure. Bitumen is a colloidal system that dissolves in trichloroethylene. This solvent is used to determine the constituent that are present in bitumen. The bitumen constituent can be classified as asphalthens and maltenes.

Bitumen can be characterized by their chemical composition and it is bitumen's chemical properties that determine its physical properties. Therefore, a basic understanding of bitumen Chemistry can help one understand how and why it behaves the way it does [12]. However, it is the chemical properties that determine its physical properties, and hence bitumen is most commonly characterized by their physical properties. The bitumen chemical microstructure model can be used to determine its basic composition using Nuclear Magnetic Resonance (NMR) and Chromatography Techniques. The Bitumen microstructure is a dispersed polar fluid, and a continuous three-dimensional association of polar molecules generally referred to as "Asphalthenes", dispersed in a fluid of non-polar or relative low-polarity molecules generally referred to as "Maltenes", 13]. All these molecules are capable of forming dipolar inter molecular bonds of varying strength. Since these intermolecular bonds are weaker than the bonds that hold the basic organic hydrocarbon constituents of bitumen together, they will break first and control the behavioral characteristics of bitumen. Therefore, bitumen's physical characteristics are a direct result of the forming, breaking and reforming of these intermolecular bonds or other properties associated with molecular superstructures [13].

\section{Properties of Bitumen}

The properties of bitumen can be defined in the same terms as the modulus of elasticity of solid materials. In the case of solids, modulus of elasticity, E is defined by Hooke's law.

\section{Viscoelasticity}

Bitumen is a visco-elastic material, hence at high temperatures, it behaves like a liquid and hence liquid flow properties like viscosity are exhibited. However, at low temperatures bitumen behaves like a solid and hence solid properties like stress and strain become relevant. Similarly, for short loading time (stress/pressure of traffic) bitumen behaves like a solid whereas for longer loading times, bitumen behaves like a liquid. The properties that bitumen exhibits in the intermediate temperature range and loading time are of great relevance as this range is very long and bitumen is handled in this temperature range most of the time [13].

\section{Adhesion}

Bitumen has excellent adhesive qualities provided the conditions are favourable. External factors such as rainfall, humidity, water $\mathrm{pH}$, dirt, durability, surface areas, absorption, moisture content, shape and weathering can have major influence on this process. However, in the presence of water, the adhesion does create some problems. Most of the aggregates used in road construction possess a weak negative charge on the surface. The bitumen aggregate bond is because of a weak dispersion force. Water is highly polar and hence it gets strongly attached to the aggregate, displacing the bituminous coating [13].

\section{Bitumen Failure in Pavement}

The most common problems related to the degradation of bitumen uses in pavements can be grouped into three categories: thermal cracking; surface deformations due to viscoelastic behaviour of the material and surface defects. The two main failure mechanisms suffered by asphalt mixtures are cracking and rutting (permanent deformation).

Cracking is usually associated to brittle fracture of bitumen at low temperatures, while rutting is associated to plastic or viscous behaviour of bitumen at high temperatures. In order to reduce cracking, bitumen has been typically modified by addition of elastomeric polymers; usually requiring mixing and shearing at high 
temperatures in order to uniformly disperse the polymers into the blends $[1,14,2]$.

Robertson et al., [12], describes bitumen behavior in terms of its failure mechanism. They describe each failure mechanisms as a function of bitumen's basic molecular chemistry.

\section{Aging}

There is the reversible and irreversible aging .Irreversible aging is generally associated with oxidation at the molecular level. This oxidation increases bitumen viscosity with age, until a point when the bitumen is able to quench (or halt) oxidation through immobilization of the most chemical reactive elements. Reversible aging is generally associated with the effect of molecular organization. Over time, the molecules within bitumen will slowly reorient themselves into a better packed, more bound system. This results in a stiffer, more rigid material. This aging can be reversed by heating and agitation. The removal of the oily constituents, resins or asphaltenes from the bitumen by selective absorption of some porous aggregates is refered to as separation.

There is no direct measure for bitumen aging; rather, aging effects are accounted for by subjecting bitumen samples to simulated aging, then conducting other standard physical test such as Viscosity, Dynamic Shear Rheometer (DSR), Bending Beam Rheometer (BBR) and The Direct Tension Test (DTT). Simulating the effect of aging is important because bitumen that possess a certain sets of properties in its original state, may possess a different set of properties after aging, such as Short-term aging and Long-term aging [15].

Typical Aging Simulation Tests Are:

i. Thin Film Oven (TFO) Test.

ii. Rolling Thin-Film Oven (RTFO) Test.

iii. Pressure Aging Vessel (PAV) Test.

\section{Stripping}

Bitumen adheres to aggregates because the polar molecules (positive charged on one side and negative on the other side) within the bitumen are attracted to the polar molecules on the aggregates' surface. Certain polar attractions are known to be disrupted by water itself (a polar molecule). Additionally, the polar molecules within bitumen will vary in their ability to bind to any one particular type of aggregates. The result is disintegration of the molecular structure [15].

\section{Moisture Damage}

Since it is a polar molecule, water is readily accepted by the polar bitumen molecules. Water can cause stripping and/ or can decrease bitumen Viscosity. It typically acts like a solvent in bitumen and result in reduced strength and increase rutting. From a chemical point of view, water should have a greater negative effect on older bitumen. As oxidation causes aging (or older), bitumen will contain more polar molecules. The more polar molecules bitumen contains, the more readily it will accept water. Therefore increase the disintegration of the molecule (binding) structure [15].

\section{Thermal Racking}

At lower temperatures, even the normally fluid non-polar molecules begin to organize into a structured form. When combined with the already structured polar molecules, bitumen is more rigid and likely to fracture rather than deformed elastically under stress. Thermal cracking can occur in all climates, hot or cold. However, it is evident when the temperature variation between day and night and between summer and winter are large since the risk of cracking increases with aging -induce brittleness [15].

\section{Fatigue Cracking}

If the molecular networks become too organized and rigid, bitumen will fracture rather than deform elastically under stress. Therefore, bitumen with higher percentage of polar, network forming molecules may be more susceptible to fatigue cracking. Cracking leads to surface damage and road based destruction. The repetitive destruction caused by traffic, initiates cracks and ultimately results in pothole formation [15].

\section{Rutting and Permanent Deformation}

If the molecular network is relatively not interconnected, bitumen will tend to deform inelastically under heavy load and high temperature and not all the deformations is recoverable. Additionally, bitumen with higher percentage of non-polar dispersing molecules are better able to flow and plastically deform because of the various polar molecules network pieces can more relative to one another due to the greater percentage of fluid non-polar molecules, rutted roads and unexpected movement of the car and deliberate evasive action by driving on the shoulder of the road. Also water can accumulate in the ruts causing aqua plane-included skidding and reduced visibility reflections [15].

\section{Chemistry of Polyethylene}

Polyethylene is an addition polymer that is produced by the polymerization of ethylene monomer units [16]. Ethylene can be polymerized by a free radical mechanism under very high pressures and temperatures with the addition of an organic peroxide radical initiator. This reaction is thought to proceed as follows:

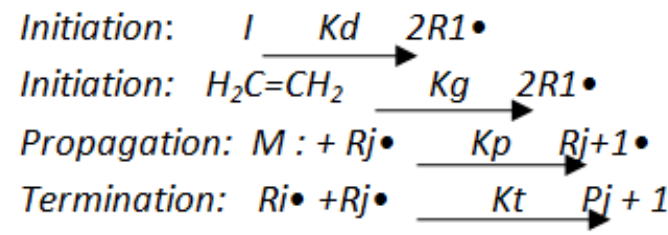


Polyethylene is produced through polymerization of ethane, which is achieved by free radical polymerization, anionic addition polymerization, ion co-ordination polymerization or cationic addition polymerization [3]. This is because ethene does not have any substituent group which influences the stability of the propagation head of the polymer. Each of these methods results in a different type of polyethylene. The process requires a highly purified ethylene feed and the operating pressure ranges from 1000 to $3000 \mathrm{~atm}$ and a temperature range of 1203000C.Temperatures exceeding 3000C cause ethylene to decompose and are not recommended in practice [16]. Therefore, the development of mathematical models to predict the process behaviour is important to ensure a stable operation, associated with an improvement in the properties of the produced polymer [17]. For initiation, usually peroxides are used, with a mixture of different initiators is used; each of them decomposes into radicals depending on the temperature. In the presence of radicals, monomer starts to react with them, forming longer and longer radicals, so-called "living polymer". The third main step in the free radical polymerization process is the termination step which ends the reaction.

\section{Bitumen Modification}

Following the failure mechanism of bitumen, there has been needed to improve its properties by addition of modifiers. Certain additives or blend of additives called bitumen modifiers can improve properties of bitumen and bituminous mixes. Bitumen treated with these modifiers is known as modified bitumen. Several literatures have reported on the assessment of the performance and the rheological properties of polymer-modified bitumen [18, 17, 19, 20]. Among these studies, Ashok et al., [21] reported that rutting resistance, indirect tensile strength and resilient modulus of the bituminous concrete mix with polymer modified bitumen is significantly improved compared with conventional bitumen.
In Nigeria, empty polyethylene sachet containers are rampant in the nook and cranny of cities. They therefore pose serious environmental problems to inhabitants especially where solid wastes are deposited in towns (urban areas) and villages (rural areas). Urban waste disposal is the responsibility of various municipalities, local government and/or city cooperations [22]. These materials are not biodegradable and when they are not properly disposed, they find their way into the rivers and water ways.

This work attempt to study the mechanical and rheological properties of bitumen-polymer (polyethylene) blend.This is important in order to understand possible conversion of the non-degradable waste into useful product. It will further go a long way in finding alternative uses for environmental waste. The aim of this study is to modify bitumen with sheared polyethylene waste for application in road pavement and the objectives of the study are to extract bitumen from samples collected from Agbabu and Loda, modify the obtained bitumen using different proportions of sheared polyethylene waste, determine the physicomechanical properties and rheological parameter of polymer modified bitumen and to determine the optimum bitumen content suitable for filler in road construction.

\section{MATERIALS AND METHODS Collection and Preparation of Bitumen and Tar Samples}

As indicated in Fig-1, raw bitumen and tar Sand samples used for this work were obtained from Agbabu and Loda in Odigbo and Irele Local Government Area of Ondo State, Nigeria. The samples were collected randomly at different locations, so as to obtain representative samples. Agbabu is located at latitude $6^{0} 35^{\prime} 19^{\prime} ' \mathrm{~N}$ and Longitude $4^{0} 50^{\prime} 3^{\prime}$ ' $\mathrm{E}$ in the tropical savanna. The raw bitumen and tar sands were extracted by Soxhlet extraction method using carbon disulphide as a solvent and stored in a clean tin-can for further analysis.

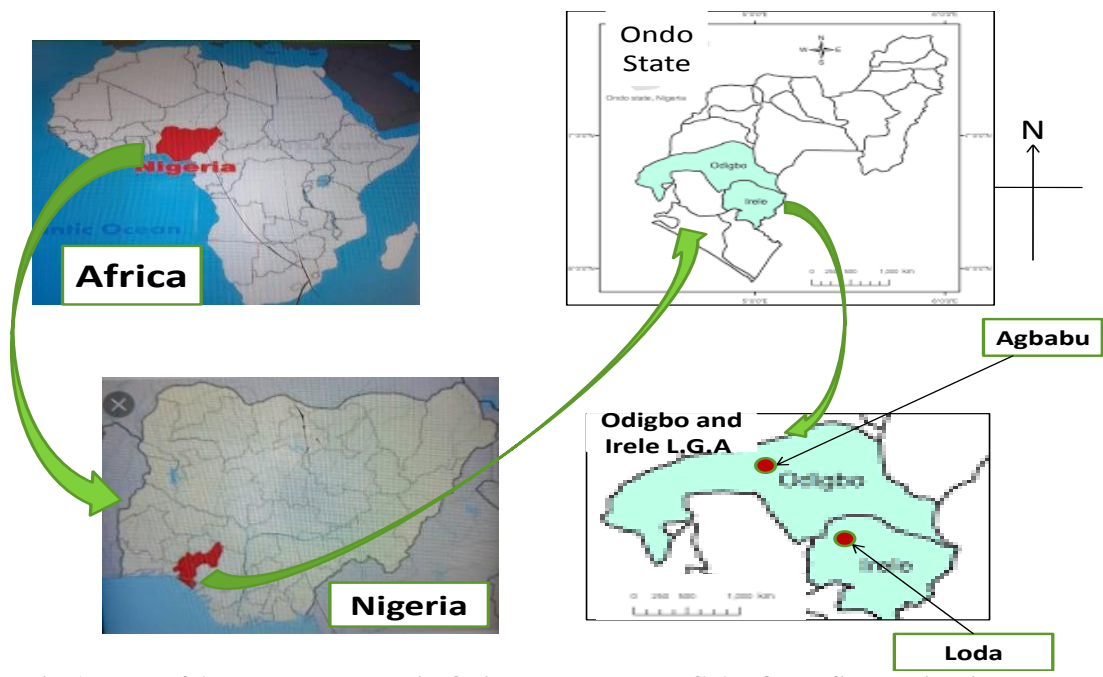

Fig-1: Map of Agbabu and Loda in Odigbo and Loda L.G.A., Ondo State, Nigeria 


\section{Collection of Waste Polyethylene Sachet}

Polyethylene bags were obtained from Owo town, Ondo state, Nigeria. The samples were pulverized and made into particle sizes. Fig 2 and 3 revealed the polyethylene waste and product after pulverization.

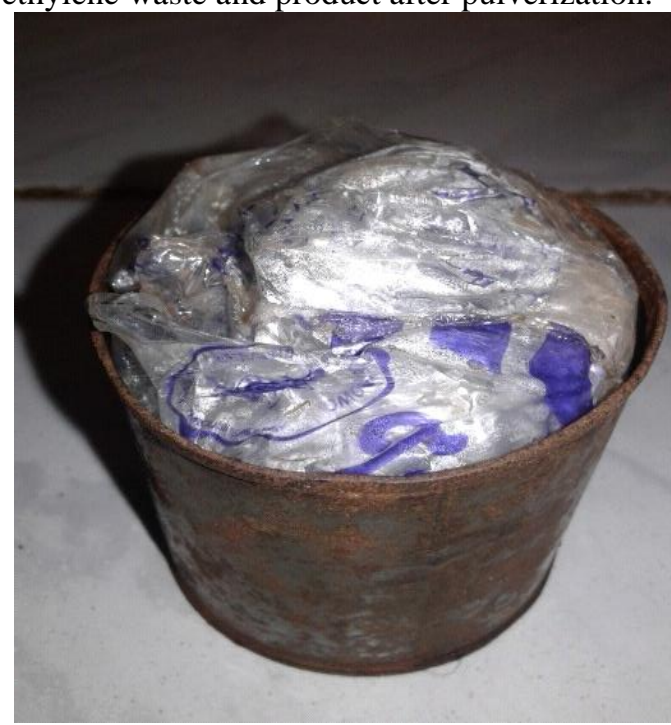

Fig-2: Polyethylene sachet waste

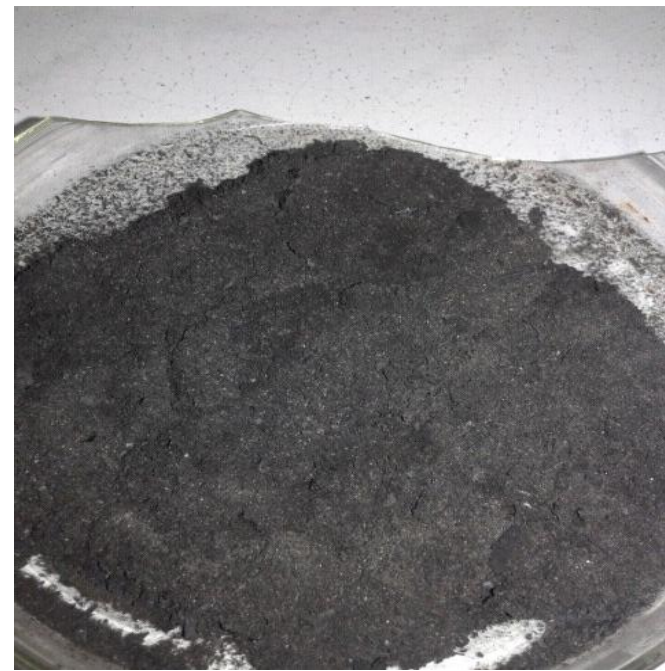

Fig-3: Sheared polyethylene sachet waste at $300^{\circ} \mathrm{C}$

\section{Preparation of Polymer-Bitumen Blends}

The extraction of bitumen samples from the raw bitumen was done using soxhlet extraction process and carbon disulphide as a solvent. A method by Fawcett et al., [23] was followed. 200grams of sheared waste polyethylene sachet were mixed in ratio 10:90, 20:80, 30:70, 40:60 and 50:50 to extracted bitumen sample from both Agbabu and loda using mechanical mixer Heidolph model RZR 2020. The mixtures of the different ratios were heated in a thermosetting oven at $300^{\circ} \mathrm{C}$ for two hours. The temperature ensures that both polymers and bitumen were always above their softening point and temperature. The mixtures were brought out and blended together mechanically while still hot at speed $2000 \pm 10 \mathrm{rpm}$. Mixing and shearing at high temperature is required in order to have uniform dispersed polymers in the blends. It was cooled at room temperature to solidify. Rheological properties of the resulting sample were determined: the penetration test, Viscosity, melting point and marshal Stability ware carried out by ASTM standards [24] and specific gravity were determination according to AOAC [25].

\section{RESULTS AND DISCUSSION}

Fig-4 showed the variation of measured values of penetration for the different blends. It can be observed that increased amount of polyethylene waste reduced the measured value of penetration reaching values as low as for 40:60 blend. The relationships between the penetration value and polymer modifier has been adequately predicted by a linear model.

Penetration at $25^{\circ} \mathrm{C}=0.88$ (polyethylene $)+17(\mathrm{STW})$ $\left(\mathrm{P}\right.$-values $\left.=0.005, \mathrm{R}^{2}=89.9\right)$

The statistical correlation between the modifiers in Agbabu and Loda with polyethylene showed that penetration value is correlated with polymer concentration.

Penetration of Sheared Polyethylene Modified Bitumen (SPMB) from Agbabu and Loda.

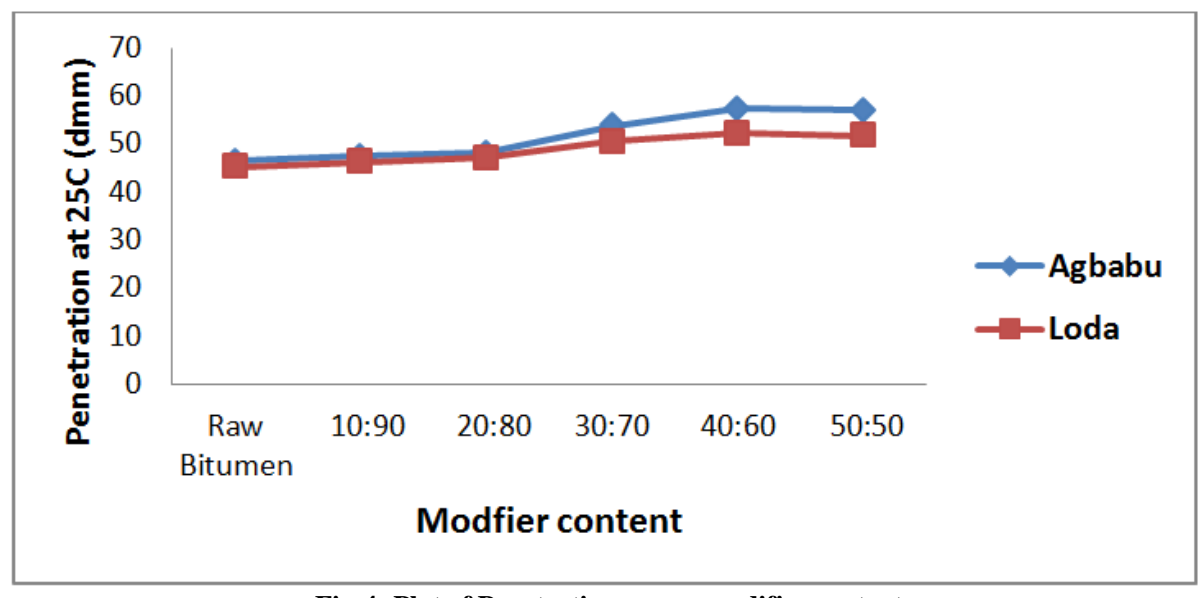

Fig-4: Plot of Penetration versus modifier content 


\section{Specific Gravity}

Fig-5 showed the values obtained for specific gravity of Polyethylene Modified Bitumen (SPMB) from Agbabu and Loda. A significant increase was observed at 10:90 from raw sample and there was no significant increase in the values from 20:80 to $40: 60$ ratios of the blends.

Specific gravity of Sheared Polyethylene Modified Bitumen (SPMB) from Agbabu and Loda.

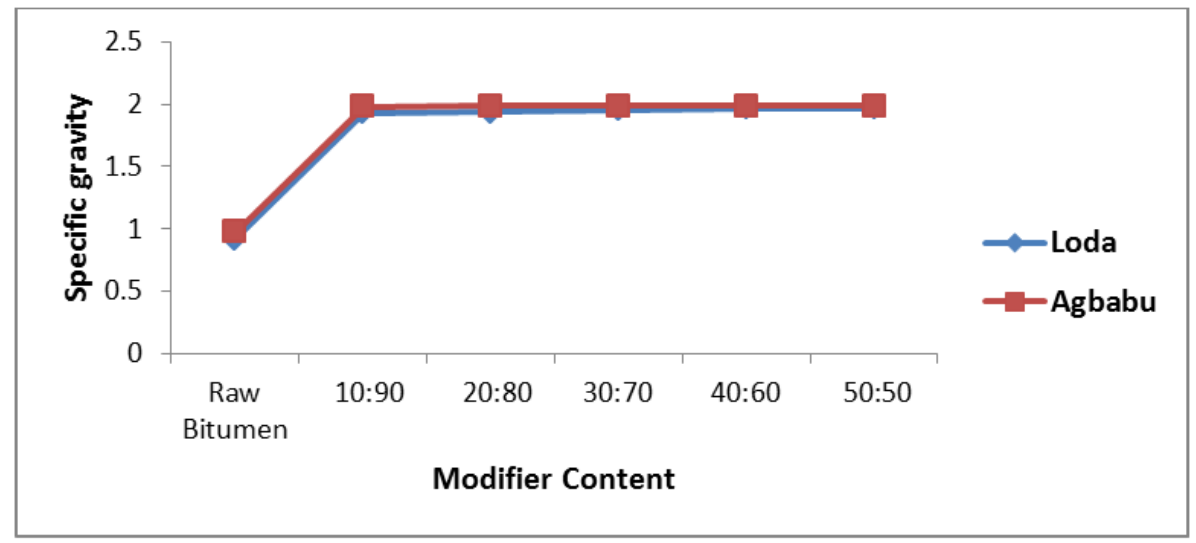

Fig-5: Plot of specific gravity versus modifier content

\section{Viscosity}

Viscosity of bitumen play improvement role in high temperature failure and therefore affect the service life. In this study, increasing viscosity was observed for modified bitumen as ratio of polyethylene increases to 60:40 ratio of bitumen / polyethylene modification before chap reduction a t 50:50 ratio. This observation might be due to lowering of the bitumen stiffness. Viscosity of material plays a prominent role in determining many aspects of road performance according to Munera and Ossa [9]. The implication of this is that addition of modifier produce a binder that is viscose for field operation as reported by Robertson $e t$ al., [12].

Viscosity of Sheared Polyethylene Modified Bitumen (SPMB) from Agbabu and Loda.

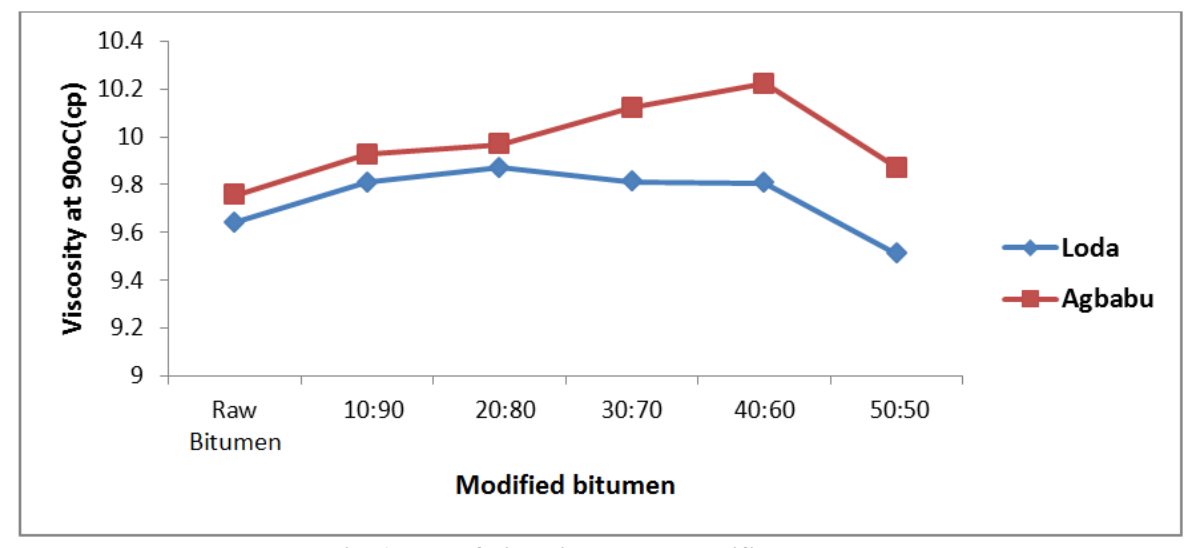

Fig-6: Plot of viscosity versus modifier content

\section{Softening Point}

Fig-7 presents the softening point measured for each of the blends as a function of modifier concentrations. It was observed from the results that the blend with 40:60 had the highest softening point temperature, reaching up to $65^{\circ} \mathrm{C}$. At 40:60 ratio, blends increases the softening point to 71.10 in polyethylene modification in Agbabu and 67.16 in Loda modification. Similarly, at 50:50 blends the decreases in softening point was observed (70.84 and 64.01) in Agbabu and modified bitumen respectively. This implies that at 40:60 loading, polyethylene showed appreciable increase in softening for Loda and Agbabu.

Softening increases with increasing modifier content. The same trend has been reported by Ashok et al., [21] for Unaged PMB-70. This trend seems to be reversal for observed viscosity. It appears the lower the viscosity, the higher the softening point.

Softening point of Sheared Polyethylene Modified Bitumen (SPMB) from Agbabu and Loda. 


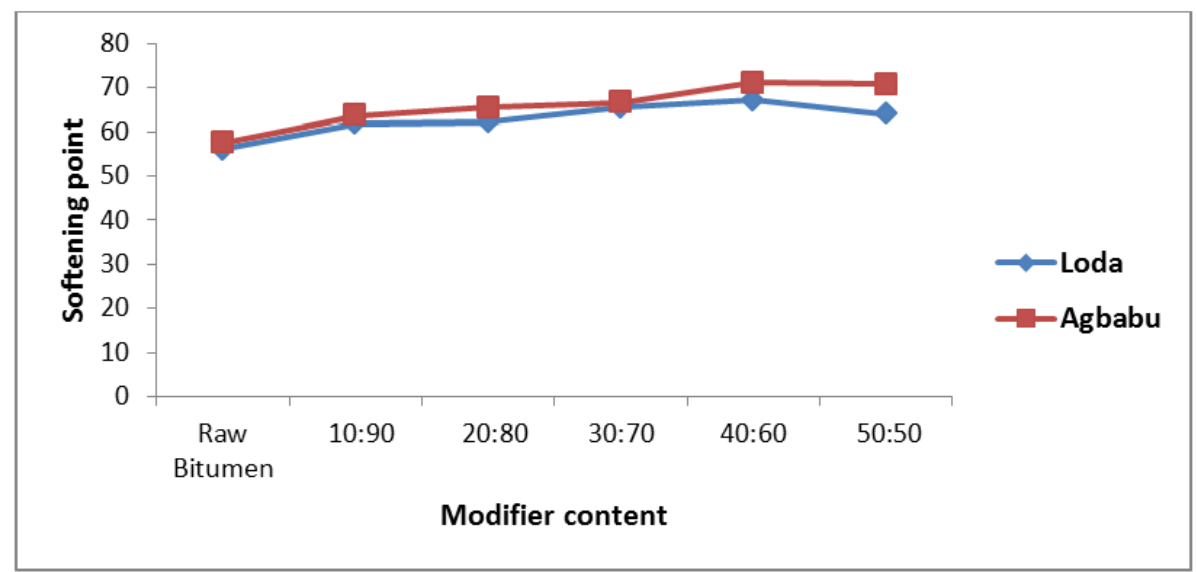

Fig-7: Plot of softening point versus modifier content

\section{Marshal Stability}

Fig-8 present the mean values of Marshall Stability for various blends of polyethylene. It is worthy to note that all modifiers showed increases in Marshall Stability as the modifier concentration increase. The highest mean value was observed at ratio 10:90(890.60) and a constant increase from 30:70 to 40:60 for Agbabu modification. This ratio has the most significant impact on the Marshall characteristics of the blends in Agbabu than Loda. This trend can be attributed to the size effect of the modifiers. The implication of this is that there is increase in stiffness the modified bitumen to soil aggregates.

Marshall Stability of Sheared Polyethylene Modified Bitumen (SPMB) from Agbabu and Loda.

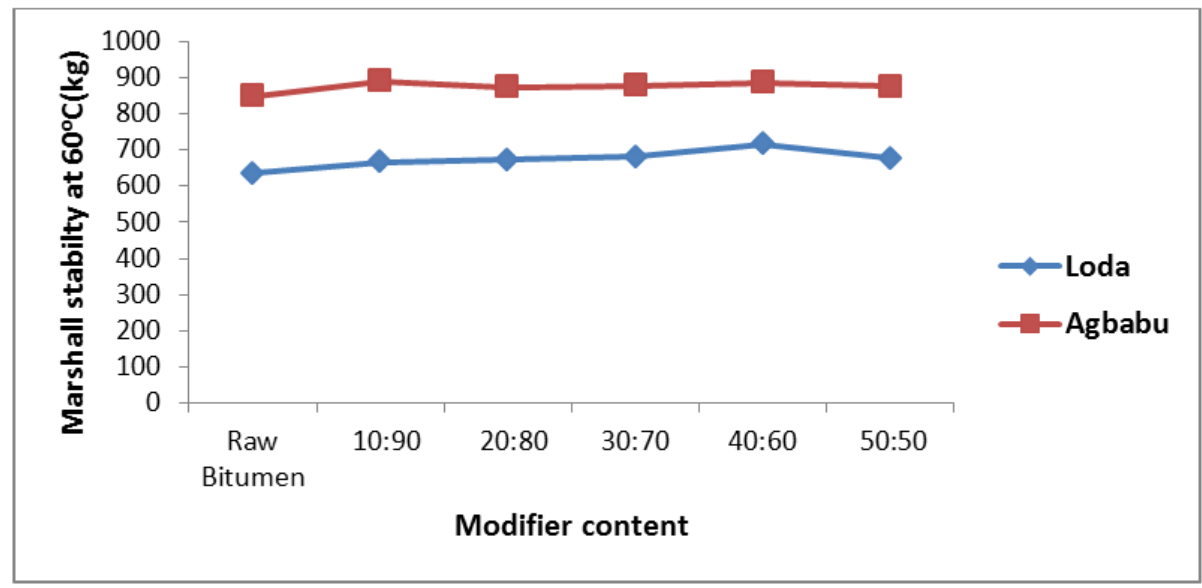

Fig-8: Plot of Marshall Stability versus modifier content

\section{Rheological Properties}

Data on rheological properties (complex modulus, phase angle and rutting) of bitumen polymer blends as a function of modifier concentrations are contained in Tables 1 and 2 .

\section{Complex Modulus}

The complex shear modulus $\left(\mathrm{G}^{*}\right)$ is a measure of a material's total resistance to deformation when constantly sheared. In this study, the complex modulus $\left(\mathrm{G}^{*}\right)$ was measured as a function of frequency at a temperature $40^{\circ} \mathrm{C}$ for base bitumen and at various blends. The results shows that the maximum complex modulus was 40:60, after this, there was significant decrease in complex modulus as modifier concentration increases. This is an indication of the maximum shear stress and shear strain due to improvement in intermolecular forces binding modifier to bitumen.

\section{Phase Angle}

Phase angle $(\boldsymbol{\delta})$ measurements are generally considered to be more profound to the chemical structures. As can be observed in the Tables 1 and 2, the trend observed showed that phase angle increases with increasing temperature. This observation agrees with the reported trend for Unaged PMB-70 [21]. However, the result showed that phase angle increase with increase modifier concentration up to 40:60 and thereafter decline by almost $2 \%$ for polyethylene respectively. This demonstrated that bitumen modified with polyethylene can withstand environment stress more than base bitumen. 
Table-1: Results of Rheological Properties of Sheared Polyethylene Modified Bitumen (SPMB) from Agbabu

\begin{tabular}{|c|c|c|c|c|c|c|}
\hline $\begin{array}{l}\text { Waste/ } \\
\text { Bitumen } \\
\%\end{array}$ & $\begin{array}{l}\text { Temp } \\
{ }^{{ }^{C}}\end{array}$ & $\begin{array}{l}\text { Complex modulusG* } \\
(\mathrm{kPa})\end{array}$ & $\begin{array}{l}\text { Phase } \\
\operatorname{angle}(\delta)\end{array}$ & $\begin{array}{l}\text { Storage } \\
\text { modulus } \\
\text { G'(kPa) }\end{array}$ & $\begin{array}{l}\text { Loss } \\
\text { modulus } \\
\text { G" (kPa) }\end{array}$ & $\begin{array}{l}\text { Rutting parameters } \\
\mathrm{G}^{*} / \operatorname{Sin} \delta(\mathrm{kPa})\end{array}$ \\
\hline \multirow[t]{3}{*}{$10: 90$} & 45 & 28.40 & 76.60 & 2.10 & 28.20 & 29.22 \\
\hline & 55 & 11.50 & 76.80 & 0.32 & 11.20 & 11.81 \\
\hline & 65 & 2.80 & 79.50 & 0.04 & 2.80 & 2.85 \\
\hline \multirow[t]{3}{*}{$20: 80$} & 45 & 29.50 & 77.10 & 2.60 & 29.40 & 30.26 \\
\hline & 55 & 11.45 & 80.20 & 0.31 & 11.40 & 11.61 \\
\hline & 65 & 3.00 & 81.70 & 0.04 & 3.00 & 3.03 \\
\hline \multirow[t]{3}{*}{$30: 70$} & 45 & 30.40 & 82.40 & 3.00 & 30.30 & 30.66 \\
\hline & 55 & 11.70 & 83.50 & 0.33 & 11.50 & 12.53 \\
\hline & 65 & 3.10 & 84.10 & 0.03 & 2.10 & 3.27 \\
\hline \multirow[t]{3}{*}{$40: 60$} & 45 & 32.50 & 88.10 & 3.10 & 32.40 & 32.52 \\
\hline & 55 & 11.90 & 90.70 & 0.33 & 11.70 & 11.90 \\
\hline & 65 & 3.50 & 92.40 & 0.02 & 3.20 & 3.50 \\
\hline \multirow[t]{3}{*}{$50: 50$} & 45 & 32.00 & 87.80 & 3.00 & 31.50 & 32.02 \\
\hline & 55 & 10.90 & 89.90 & 0.02 & 11.10 & 10.90 \\
\hline & 65 & 3.30 & 90.70 & 2.90 & 3.10 & 3.30 \\
\hline
\end{tabular}

Table-2: Results of Rheological Properties of Sheared Polyethylene Modified Bitumen (SPMB) from Loda

\begin{tabular}{|c|c|c|c|c|c|c|}
\hline $\begin{array}{l}\text { Waste/ } \\
\text { Bitumen } \\
\%\end{array}$ & $\begin{array}{l}\text { Temp } \\
{ }^{{ }^{\circ}} \mathrm{C}\end{array}$ & $\begin{array}{l}\text { Complex } \\
\text { modulusG* (kPa) }\end{array}$ & $\begin{array}{l}\text { Phase } \\
\text { angle }(\delta)\end{array}$ & $\begin{array}{l}\text { Storage } \\
\text { modulus } \\
\text { G'(kPa) }\end{array}$ & $\begin{array}{l}\text { Loss } \\
\text { modulus } \\
\text { G" (kPa) }\end{array}$ & $\begin{array}{l}\text { Rutting parameters } \\
\mathbf{G}^{* / \operatorname{Sin} \delta}(\mathrm{kPa})\end{array}$ \\
\hline \multirow[t]{3}{*}{ 10:90 } & 45 & 26.70 & 65.50 & 2.50 & 26.60 & 29.34 \\
\hline & 55 & 8.50 & 72.40 & 0.39 & 8.30 & 8.92 \\
\hline & 65 & 2.60 & 74.70 & 0.04 & 2.60 & 2.95 \\
\hline \multirow[t]{3}{*}{$20: 80$} & 45 & 27.50 & 70.10 & 2.55 & 27.00 & 29.23 \\
\hline & 55 & 9.00 & 73.20 & 0.39 & 8.50 & 9.40 \\
\hline & 65 & 2.80 & 75.10 & 0.05 & 2.70 & 2.9 \\
\hline \multirow{3}{*}{ 30:70 } & 45 & 29.40 & 75.50 & 2.80 & 29.35 & 30.37 \\
\hline & 55 & 9.30 & 76.70 & 0.40 & 9.20 & 9.56 \\
\hline & 65 & 3.40 & 76.90 & 0.06 & 3.40 & 3.49 \\
\hline \multirow[t]{3}{*}{$40: 60$} & 45 & 31.30 & 78.50 & 3.20 & 31.10 & 31.94 \\
\hline & 55 & 10.50 & 79.20 & 0.52 & 10.30 & 10.69 \\
\hline & 65 & 3.70 & 80.20 & 0.06 & 3.60 & 3.76 \\
\hline \multirow[t]{3}{*}{ 50:50 } & 45 & 31.00 & 77.60 & 3.10 & 29.90 & 31.74 \\
\hline & 55 & 9.50 & 78.50 & 0.45 & 9.40 & 9.70 \\
\hline & 65 & 3.50 & 79.20 & 0.06 & 3.3 & 3.56 \\
\hline
\end{tabular}

\section{Rutting}

Rutting is evaluated by determining the ratio of the complex shear modulus $\left(\mathrm{G}^{*}\right)$ to the sin of phase angle ( $\delta$ ).Rutting measures the aging period in a bitumen as a result of deformity of the surface tension due to temperature changes. The trend observed (Tables 1 and 2) showed that increase in temperature has significant effect on rutting. This trend agrees with the reported for Unaged 60/70 Bitumen and Unaged PMB70 [21]. The trend is the reverse of that of phase angle. Reduction in the complex shear modulus and increase in the phase angle increases the aging. Aging can be short-term or long term. Long term aging occurs after a long period of time after pavement and short-term occurs during mixing.

\section{DISCUSSION}

Improved characteristic of bituminous binder such as viscosity, penetration, softening point, complex modulus and phase angle in modification of bitumen has been observed. The addition of plastic-elastomers has been to increase the properties of bitumen in proportion to the amount of modifiers.

Fig-4 presents the results of penetration tests at $25^{\circ} \mathrm{C}$ for sheared Polyethylene for bitumen modification. The penetration of modified bitumen increases with increasing modifier content from 30:70 to 40:60. The observation showed that adding a certain amount of modifier to bitumen can slightly decrease the shear stiffness. This is an indication for ability to withstand pressure that may act on it and this is higher in Agbabu bitumen. The observed trend was between 30:70 and 40:60, which ranges from 48.20-57.35 in Agbabu and 47.10-52.15 in Loda for sheared polyethylene modifier respectively. However, these values were the least values obtained in the two modifiers, but higher than the value obtained for bituminous Concrete with $60 / 70$ Grade Bitumen (2.95) and bituminous Concrete Mix with PMB-70(3.10) reported by Ashok et al., [21] at the same temperature. 
Fig-5 presents the values obtained for specific gravity of polymer modified bitumen. The results showed that specific gravity (0.972) and 0.9754 for raw bitumen. The values were comparable with the permissible limit $>0.99$ set by the Indian Standard Institute on Paving bitumen Specification (IS: 73, 2001) [26] for bitumen use in road pavement. The results showed that specific gravity of modified bitumen remain constant despite Increase in modifier concentration. The values obtained in this study significance different from the value 0.9517 obtained by Sharma et al., [27]. The value was comparably within the permissible limit $>0.99$ set by the Indian Standard Institute for paving bitumen Specification (IS: 73, 2001) [26].

Fig-6 presents the Viscosities at $60^{\circ} \mathrm{C}$ in $\mathrm{Pa} / \mathrm{Sec}$ of the polymer modified bitumen. Worthy of note in these results is reduction in viscosities of the modified bitumen compared with base bitumen especially at 30:70 before the increase in viscosity was observed for modified bitumen as ratio of polyethylene increases to 60:40 ratio of bitumen / polyethylene modification in both samples before chap reduction at 50:50 ratios. The reduction in viscosity at $30 ; 70$ ratio in both can be attributed to consequential reduction in the surface tension between the aggregate and binders thereby expelling air and increasing interfacial cohesion between the bitumen and modifier aggregate [28].

The values observed for softening point in modifier concentrations was as shown in fig.7. The results revealed that the blend with 40:60 had the highest softening point temperature, reaching up to $65^{\circ} \mathrm{C}$ at 40:60 ratio blends in Agbabu (71.10) and Loda (67.16) modification. Likewise, at 50:50 blends the decreases in softening point was observed (70.84 and 64.01) in Agbabu and Loda modified bitumen respectively. This indicated that at 40:60 loading, polyethylene showed appreciable increase in softening for Loda and Agbabu.

Softening increases with increasing modifier content. The same trend has been reported by Ashok et al., [21] for Unaged PMB-70. This trend seems to be reversal for observed viscosity. It appears the lower the viscosity, the higher the softening point.

Fig-8 presents the effects of Polyethylene modifiers on Marshall Stability of bitumen. Marshall Stability test is an indirect measure of the stiffness of bitumen makes it suitable for use in construction works. Polyethylene modified bitumen showed the highest stability at 10.90 with values of 667.2 and 890.60 at Loda and Agbabu respectively.

Marshall Stability $(\mathrm{kg})\left(\right.$ at $\left.60^{\circ} \mathrm{C}\right)$ for Agbabu Modified bitumen were 8574.50 $\pm 0.50,8714.0 \pm 0.40$ and $885.00 \pm 0.40$ for ratio $20: 80,30: 70,40: 60$ and $672.50 \pm 0.50, \quad 681.10 \pm 0.50$ and $715.20 \pm 0.40$ for modified bitumen from Loda respectively. Marshall Stability test is an indirect measure of the stiffness of bitumen makes it suitable for use in construction works. As shown in Figures 22 and 23, polyethylene modified bitumen showed the highest peak stability at 40:60 with values of $885.00 \pm 0.40$ and $715.20 \pm 0.40$ at Loda and Agbabu respectively.

The percentage increase in modified bitumen samples can reduce their shear modulus as indicated in Table 1 and 2. This was observed as decline set inn at ratio 50:50 leading to damping effect at a corresponding confining temperature and pressures at 40:60. Thus, it can be concluded that adding a certain amount of sheared polyethylene waste to bitumen can slightly decrease the shear stiffness, whereas significantly increases damping. The results did not agree with the characteristic properties of asphalt obtained from other test reported by Murat et al., [29] of rubber-modified asphalt at $20 \%$.

The complex shear modulus $\left(\mathrm{G}^{*}\right)$ is a measure of a material's total resistance to deformation when constantly sheared. That average values of $\mathrm{G}^{*}$ for the various binders used in this study, as tested over temperature ranges from $45{ }^{\circ} \mathrm{C}$ to $65{ }^{\circ} \mathrm{C}$ as rutting is predominant on the pavements at these temperatures. With all levels of sheared polyethylene, the values of $\mathrm{G}^{*}$ decreases with temperature increased. It can be noted that the addition of 40:60 of polyethylene increased $\mathrm{G}^{*}$ significantly as compared to base bitumen, though, the minimum specified value at which bitumen can contribute to rutting is $2.2 \mathrm{kPa}$ as reported by Sharma et al., [27] is exceeded. This trend is expected because at temperature $30-40{ }^{\circ} \mathrm{C}$ presence of modifiers provides a significant elasticity capacity.

\section{CONCLUSION}

From the present study, we can conclude that each of the modifier examined shows rheological properties enhancement. It was observed that the percentages of sheared polyethylene modified bitumen (SpMB) samples obtained from Agbabu and Loda had high physico-mechanical characteristics such as Marshall Stability at $60^{\circ} \mathrm{C}$, viscosity at $90^{\circ} \mathrm{C}$ and the penetration at $60^{\circ} \mathrm{C}$ Agbabu than Loda in ratio10:90 to 40:60 respectively.

However, the relative increase in the penetration test of the bitumen modified samples obtained from Agbabu, may be attributed to the increase sheared Stress in polyethelene waste content as a result of its intermolecular forces.

The rutting parameters obtained from the rheological properties indicated that sheared polyethylene waste modified bitumen samples from Agbabu and Loda can withstand many of the defects accountable to paving deformation and aging as there was a decrease in the rutting parameter with increase in 
temperature from $45^{\circ} \mathrm{C}$ to $65^{\circ} \mathrm{C}$ due to significant decrease in rutting parameters with increase in temperatures.

There is a decrease in complex modulus and increase in the phase angle of the modified bitumen from the modifiers in ratio 10:90 to 40: 60 due to decline in shear stress and shear strain at ratio 50:50 at the same temperature range. The decrease in Complex modulus begins and phase angle is an indication of the maximum shear stress and shear strain.

Generally, the tensile strength of the modified bitumen at 40:60 modifications is higher at $45{ }^{\circ} \mathrm{C}$, which contributed to the maximum rutting parameters obtained and good performance in road paving. Both modified bitumen at 40:60 provide better performance for paving roads, however, Agbabu modified bitumen at 40:60 had desirable characteristic and it is economical than Loda.

\section{Author Contributions}

G. Aladekoyi sought for the study authorization from the relevant government institutions. He developed the study methodology that also comprised preparing a checklist that was used in data collection. G. Aladekoyi and Dr. E.G. Olumayede analyzed the samples and interpreted the data. Dr. E. G. Olumayede undertook a literature review that included the introductory background information and the theoretical context. Both authors edited the paper to ensure completeness and consistency with the journal's formatting guidelines.

\section{ACKNOWLEDGEMENT}

The authors would like to thank The Director of The Research Unit of Rufus Giwa Polytechnic, Owo, Ondo State, Nigeria for granting the permit to undertake the study. Appreciation also goes to the Rector, Rufus Giwa Polytechnic, Owo, Ondo State who provided clearance for collecting data. Special acknowledgement correspondingly goes to Mr Ogunmola, who provided the survey maps that were used to determine the spatial extent of conformity with the approved land subdivision regulations.

\section{Conflict of Intrest}

The authors declare that there are no conflicts of interest regarding the publication of this manuscript. In addition, the ethical issues; including plagiarism, informed consent, misconduct, data fabrication and/or falsification, double publication and/or submission, redundancy has been completely observed by the authors

\author{
Abbreviations (Nomenclatures): \\ $\mathrm{AOAC}=$ Association of Official Analytical \\ Chemist \\ ASTM= American Standard for Testing and \\ Materials \\ Atm $=$ Atmosphere \\ $\mathrm{G}^{*}=$ Complex modulus \\ $\mathrm{G}^{\prime}=$ Storage modulus \\ G"= Loss modulus \\ $\mathrm{PMB}=$ Polymer Modified Bitumen \\ $\mathrm{SPMB}=$ Sheared Polymer Modified Bitumen
}

\section{Graphical Illustration}

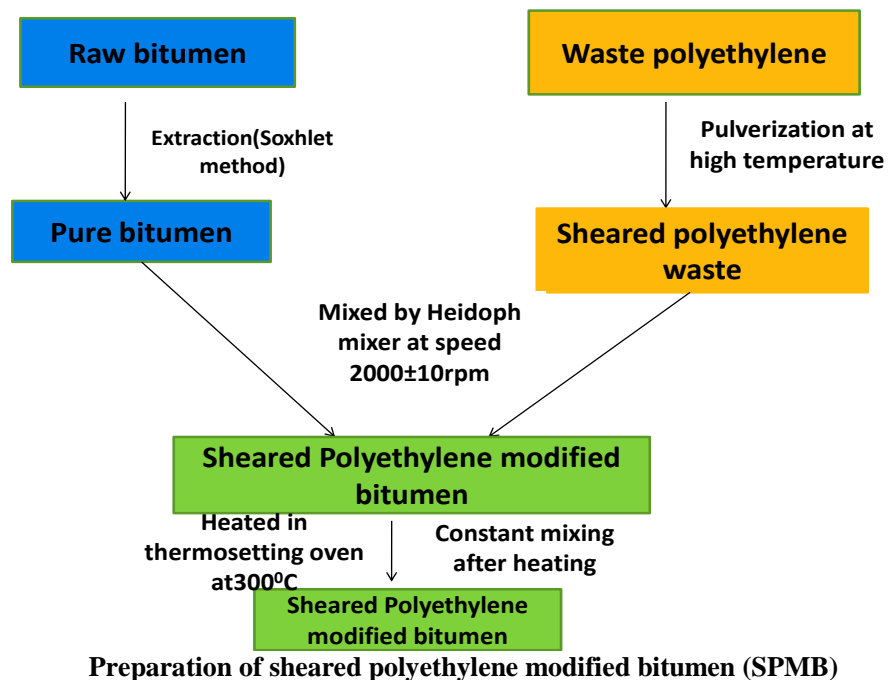

\section{REFERENCES}

1. Chen, J. S., Liao, M. C., \& Shiah, M. S. (2002). Asphalt modified by styrene-butadiene-styrene triblock copolymer: Morphology and model. Journal of materials in civil engineering, 14(3), 224-229.

2. Masson, J. F., Polomark, G., \& Collins, P. (2005). Glass transitions and amorphous phases in SBSbitumen blends. Thermochimica Acta, 436(1-2), 96-100. 
3. Collins, J. H., Bouldin, M. G., Gelles, R., \& Berker, A. (1991). Improved performance of paving asphalts by polymer modification (with discussion). Journal of the Association of Asphalt Paving Technologists, 60:43-36.

4. Anderson, D. A., \& Kennedy, T. W. (1993). Development of SHRP binder specification (with discussion). Journal of the Association of Asphalt Paving Technologists, 62:481-507.

5. García-Morales, M., Partal, P., Navarro, F. J., Martínez-Boza, F., Mackley, M. R., \& Gallegos, C. (2004). The rheology of recycled EVA/LDPE modified bitumen. Rheologica Acta, 43(5), 482-490.

6. Polacco, G., Berlincioni, S., Biondi, D., Stastna, J., \& Zanzotto, L. (2005). Asphalt modification with different polyethylene-based polymers. European polymer journal, 41(12), 2831-2844.

7. González, V., Martínez-Boza, F. J., Navarro, F. J., Gallegos, C., Pérez-Lepe, A., \& Páez, A. (2010). Thermomechanical properties of bitumen modified with crumb tire rubber and polymeric additives. Fuel Processing Technology,91(9), 1033-1039.

8. Frantzis, P. (2003). Development of crumb rubber reinforced bituminous binder under laboratory conditions. Journal of materials science, 38(7), 1397-1401.

9. Munera, J. C., \& Ossa, E. A. (2014). Polymer modified bitumen: Optimization and selection. http://dx.doi.org/10.1016/j.matdes.2014.05.00.

10. Mohamed, A. A., Omar, H., Hamzah, M. O., \& Ismail, H. (2009). Rheological properties of crumb rubber-modified bitumen containing antioxidant. the Arabian journal for science and engineering, 34 .

11. Temitope, A. K., Abayomi, O. O., Ruth, A. O., \& Adeola, A. P. (2015). A pilot recycling of plastic pure water sachets/bottles into composite floor tiles: a case study from selected dumping site in Ogbomoso. J Mater Sci Eng,4(6):1-5.

12. Robertson, M., Macleod, K., \& Luke, J. (1991). Journal of Geotechnical and Geoenvironmental engineering. 137(4):443.

13. Little, J. A., Jhill, D. G., \& Hawks, D. J. (1994). Deformations Incorporating Gigid Structures in Mathematical Methods in Biomedical Image Analysis. San Francisco, California (USA). IEEE Computer Society Press. 104-113.

14. Navarro, F. J., Partal, P., Martınez-Boza, F., \& Gallegos, C. (2004). Thermo-rheological behaviour and storage stability of ground tire rubber-modified bitumens. Fuel, 83(14-15), 2041-2049.

15. Roberts, F. L., Kandhal, P. S., Brown, E. R., Lee, D. Y., \& Kennedy, T. W. (1996). Hot Mix Asphalt Material, Mixture Design and Construction, $2^{\text {nd }}$ Ed. Lanhan MD, NAPA Research and Education Foundation.

16. Dhib, R., \& Al-Nidawy, N. (2002). Modelling of free radical polymerisation of ethylene using difunctional initiators. Chemical engineering science, 57(14), 2735-2746.

17. Chen, Z., Zhang, H., Zhu, C., \& Zhao, B. (2015). Rheological examination of aging in bitumen with inorganic nanoparticles and organic expanded vermiculite. Construction and Building Materials, 101, 884-891.

18. Alonso, S., Medina-Torres, L., Zitzumbo, R., \& Avalos, F. (2010). Rheology of asphalt and styrene-butadiene blends. Journal of materials science, 45(10), 2591-2597.

19. Dondi, G., Vignali, V., Pettinari, M., Mazzotta, F., Simone, A., \& Sangiorgi, C. (2014). Modeling the DSR complex shear modulus of asphalt binder using 3D discrete element approach. Construction and building Materials, 54, 236-246.

20. Zhang, H., Jia, X., Yu, J., \& Xue, L. (2013). Effect of expanded vermiculite on microstructures and aging properties of styrene-butadiene-styrene copolymer modified bitumen. Construction and Building Materials, 40, 224-230.

21. Pareek, A., Gupta, T., \& Sharma, R. K. (2012). Performance of polymer modified bitumen for flexible pavements. International journal of structural and civil engineering research, 1(1), 7786.

22. Ramasastry, C. V. (1988). Estimation of solid wastes in Bendel State Nigeria. Environmental Issues and Management in Nigeria Development. PO Sada and FO Odemerho (Eds.). Ibadan, Evans Brothers Publishing Company Limited.

23. Fawcett, A. H., McNally, T., McNally, G. M., Andrews, F., \& Clarke, J. (1999). Blends of bitumen with polyethylenes. Polymer, 40(23), 6337-6349.

24. ASTM. (2002). Standard Test Method for Industrial Detamination of Carbon, Hydrogen, and Nitrogen in Petroleum Products and Lubricants. ASTM International d-5291, West Conshohocken, USA.

25. AOAC. (2000). Official Methods of Analysis. Association of Official analytical chemist $15^{\text {th }}$ edition, Washington DC, USA. .

26. Indian Standard. (2001).' 'Paving bitumen specification" indian Standard Institute, new Delhi, India. Sp:73.

27. Pareek, A., Gupta, T., \& Sharma, R. K. (2012). Performance of polymer modified bitumen for flexible pavements. International journal of structural and civil engineering research, 1(1), 7786.

28. Huh, J. D. (2012). Temperature-Adjusted and Modified Recycled ASCON Composition for Reusing $100 \%$ of Waste ASCON for Road Pavement, and Method for Manufacturing Same. US Patent 20120167802 A1. 2012.

29. Karacasu, M., Okur, V., \& Er, A. (2015). A study on the rheological properties of recycled rubbermodified asphalt mixtures. The Scientific World Journal, 2015. 